\title{
The Prevalence of Wheezing and its Association with Body Mass Index and Abdominal Obesity in Children
}

\author{
Rita De CÁssia Ribeiro Silva, B.SC., PH.D., ${ }^{1, *}$ ANA MARlúCIA Oliveira Assis, B.SC., PH.D., ${ }^{1}$ \\ Marilda Souza GonCAlves, B.SC., PH.D. ${ }^{3}$ Rosemeire LeOVigildo FiaCCONE, B.MATHSC., PH.D. ${ }^{4}$ \\ Sheila Maria Alvim Matos, B.SC., PH.D., ${ }^{5}$ Maurício Lima Barreto, M.D., PH.D., ${ }^{5}$ \\ Elizabete De Jesus Pinto, B.MAThsC., ${ }^{1}$ LuCE Alves da Silva, B.SC., ${ }^{1}$ \\ Laura Cunha Rodrigues, M.D., Ph.D. ${ }^{6}$ And NeuZa Maria AlCANTARA-Neves, M.D., Ph.D. ${ }^{2}$ \\ ${ }^{1}$ Departamento de Ciência da Nutrição, Escola de Nutrição, Universidade Federal da Bahia, Salvador, Brazil. \\ ${ }^{2}$ Departamento de Ciências da Biointeração, Instituto de Ciências da Saúde, Universidade Federal da Bahia, Salvador, Brazil. \\ ${ }^{3}$ Centro de Pesquisas Gonçalo Moniz-FIOCRUZ-Bahia/Faculdade de Farmacia, Universidade Federal da Bahia, Salvador, Brazil. \\ ${ }^{4}$ Instituto de Matemática, Universidade Federal da Bahia, Salvador, Brazil. \\ ${ }^{5}$ Instituto de Saúde Coletiva, Universidade Federal da Bahia, Salvador, Brazil. \\ ${ }^{6}$ Department of Epidemiology and Population Health, London School of Hygiene and Tropical Medicine (LSHTM), London, UK.
}

\begin{abstract}
Objective. To evaluate the relative importance of body mass index (BMI) and abdominal obesity in the prevalence of wheezing in Brazilian children. Materials and methods. This is a cross-sectional study of male and female students, 6-12 years old, from the public elementary schools of São Francisco do Conde, Bahia, Northeast Brazil. Reports of wheezing in the past 12 months were collected using a questionnaire from the International Study of Asthma and Allergies in Childhood Program (ISAAC) phase III, adapted to Portuguese. Anthropometric, demographic, and socioeconomic information was collected. Multivariate logistic regression analyses were used to assess the associations of interest. Results. Of the children surveyed, $10.6 \%$ reported wheezing. Excess weight was observed in $16.2 \%, 10.5 \%$, and $7.9 \%$ of the sample, measured by BMI, waist circumference (WC), and the waist-to-height ratio (WHtR), respectively. The percentage of patients with wheezing attributable to $\mathrm{BMI} \geq 85$ th percentile (8.2\%) slightly exceeded those identified with abdominal obesity, WC $\geq 80$ th percentile $(7.3 \%)$ and $\mathrm{WHtR}>0.5$ (7.1\%). Conclusion. The results suggest that an excess of fat deposits, either in the abdominal region or elsewhere in the body, increased the risk of wheezing. Since obesity is an important public health problem worldwide, control of this problem may partially reduce the occurrence of wheezing in youth.
\end{abstract}

Keywords abdominal obesity, body mass index, wheezing

\section{INTRODUCTION}

It is estimated that approximately 300 million people of all ages worldwide are asthmatic, with significant variations in prevalence among different countries and regions (1). The International Study of Asthma and Allergies in Childhood (ISAAC) found an average prevalence of $24.3 \%$ among young Brazilians (2). The prevalence of childhood asthma has increased dramatically over the last decades (1). Many factors have been proposed to explain the increasing asthma rates, including genetic, environmental, economic, and psychosocial aspects $(3,4)$.

Currently, obesity is a major health problem in both developed and developing countries (5). Reported data from Brazil indicate an increased prevalence of overweight and obese children and adolescents in recent decades (6). Currently, $34.8 \%$ of Brazilian children aged between 5 and 9 years and $21.5 \%$ aged between 10 and 18 years are overweight or obese (7). Based on the parallel rise in the prevalence of asthma and in the prevalence of obesity in

*Corresponding author: Rita de Cássia Ribeiro Silva, Departamento de Ciência da Nutrição, Escola de Nutrição, Universidade Federal da Bahia, Rua Desembargador Oscar Dantas, Graça-CEP, Salvador-Ba, Bahia, Brazil. E-mail: rcrsilva@ufba.br recent decades, and the existence of potential mechanisms, a connection between these two conditions has been postulated.

Obesity is a known risk factor for diabetes, cardiovascular disease, and other chronic diseases, thus influencing the morbidity and mortality of populations (8). Some studies have shown an association between obesity and both wheezing and asthma (9). Decreased pulmonary functional residual capacity and tidal volume described in obese individuals have been cited as predictors for either respiratory symptoms or more fundamental changes in the airways leading to asthma (10). However, the relationship between obesity and wheezing/asthma in youth remains controversial (9).

Studies evaluating the influence of obesity on the occurrence of asthma have commonly used body mass index (BMI) as a measure of adiposity; however, problems with this marker of adiposity have been described in the literature. In addition to other limitations, BMI does not indicate body composition and body fat distribution (11). Other studies point to waist circumference (WC) (12-14), waist-to-height ratio (WHtR) (13), and the conicity index (CI) (15) as better markers than BMI for predicting cardiovascular risk factors in adults. A growing number of 
studies have documented that WHtR is superior to WC and BMI in predicting cardiovascular risk factors in adults $(12,16)$. Wheezing is a clinical manifestation that is characteristic of asthma (17). The investigation of the role of fat distribution in the occurrence of both wheezing and asthma among children and adolescents has been neglected (18, 19) (20). Thus, this study aimed to evaluate the relative importance of BMI and abdominal obesity in the prevalence of wheezing in children and adolescents from a lowincome population of a tropical Brazilian town.

\section{MATERIALS AND METHODS}

\section{Study Design}

A cross-sectional design was used to study 6- to 12-year-old children living in São Francisco do Conde (SFC), a municipality located in the metropolitan region of Salvador, Northeast Brazil. This municipality has 33,183 inhabitants and a high urbanization rate $(80.2 \%)$. Economically, the municipality has the third highest development index in the state of Bahia, and the city council is the largest local employer. However, this region experiences challenges in certain areas, including its social development index (30), level of education (139), and health indicators (178) (21).

We used data from the Education Department of the Municipality of SFC for the year 2010 to estimate the sample. Of 3734 registered students, 2649 were from rural areas and 1085 were from urban areas. These students were distributed across 22 schools in the county school system. To minimize travel costs and time for subject recruitment, the nine schools with 150 or more students were included in the sample. All students aged 6-12 years in each selected school were eligible for the study. Since the prevalence of respiratory allergies varies from $15 \%$ to $40 \%$, the sample sizes of 531 and 834 students from urban and rural areas, respectively, were determined, taking into account a $3 \%$ error and a $95 \%$ level of confidence. We added $10 \%$ to the total sample size to account for student declining to participate in the study, resulting in 1500 students.

\section{Procedures}

Data were collected from August to December 2010 by qualified and trained personnel. The principal of each selected school received a letter that included an explanation of the study's objectives and methodology and an invitation for their students to participate in the research study. The students' parents attended informational meetings at which they received extensive information concerning the project and were invited to enrol their children in the study. Participating parents signed a consent form and were invited to complete the study questionnaires. All anthropometric measurements were completed in the school by properly trained interviewers.

\section{Outcome Variable}

The prevalence of wheezing was measured using a previously validated ISAAC phase III questionnaire translated into Portuguese (22). For this study, wheezing was defined based on the following two questions: (1) Has your child ever experienced asthma or wheezing in his/her lifetime? and (2) In the last 12 months, has your child experienced wheezing? The children whose parents provided positive answers to both questions or to the second question only were considered as cases.

\section{Main Independent Variable}

Anthropometric Status. Each participant's weight was obtained using a Master ${ }^{\circledR}$ portable digital scale and height was measured using a Leicester Height Measure ${ }^{\circledR}$ portable stadiometer (Seca, Hamburg, Germany). The measurements were performed in duplicate using the techniques of Lohman, Roche, and Martorell (1988) (23). To assess anthropometric status, tables from the World Health Organization (WHO) (2007) (24) with percentile values of BMI $\left[\mathrm{BMI}=\right.$ weight $(\mathrm{kg}) /$ height $\left.(\mathrm{m})^{2}\right]$ according to age and sex were used as reference. For classification to an anthropometric status, we used the WHO 2006 (25) proposal: underweight $(<3 \mathrm{rd}$ percentile), normal weight ( $\geq 3$ rd percentile and $<85$ th percentile, reference category), overweight ( $\geq 85$ th percentile and $<97$ th percentile), and obese ( $\geq 97$ th percentile). For analysis, the overweight and obese categories were aggregated. Therefore, children with excess BMI were situated on or above the 85 th percentile. WC measurement was performed using an inelastic tape, graduated in centimeters and millimeters, according to procedures described by Gillum et al. (26). We used the cutoff points proposed by Taylor et al. (27), which identify abdominal obesity as WC $\geq$ P80. The WHtR was obtained by calculating the ratio of waist circumference $(\mathrm{cm})$ to height $(\mathrm{cm})$, with a cutoff value $>0.5$ for abdominal obesity (28).

\section{Confounding Variables}

Level of Physical Activity. To evaluate the frequency of physical activity, we used the International Physical Activity Questionnaire (IPAQ), which assesses physical activity for leisure, transport, work, and domestic purposes in the past week (28). This information allowed us to estimate the weekly time spent in physical activities by asking about the time and the frequency, during the past week, of moderate and vigorous activities and walking (28). For this study, the final score was dichotomized using a cutoff of 300 minutes/week of moderate or vigorous physical activity (29). Children with $\geq 300$ minutes of activity per week were considered active (reference category) and children with $<300$ minutes per week were classified as inactive.

\section{Pubertal Development}

Evaluation of the stage of sexual maturity was based on breast and pubic hair characteristics in girls and genitals and pubic hair in boys. Based on this staging, adolescents were grouped according to categories described by Marshall and Tanner $(30,31)$ into pre-pubescent (reference category) and pubescent. The identification of these stages 
was made by self-description with the help of portraits provided by the interviewers.

\section{Other Variables}

Other variables used in the study included the following: sex (male, female reference category), age ( $<10$ years, $\geq 10$ years reference category), education of caregiver $(\leq 4$ th grade, $>4$ th grade reference category), household location (urban, rural reference category), per capita income ( $<1$ minimum salary (MS), $\geq 1$ MS reference category), number of people living in the household $(>3, \leq 3$ reference category), and presence of smokers in the house (no reference category, yes).

\section{Statistical Analysis}

For processing and construction of the database, we used Epi Info version 6.04 (Centers for Disease Control and Prevention, Atlanta, USA). Data were entered in duplicate after reviewing the questionnaires and correcting errors from the coding field.

The characteristics of the population were identified by means of descriptive analysis using categorized data for prevalence and mean and the standard deviation for continuous variables. The study of the importance of BMI, $\mathrm{WC}$, and WHtR initially involved the evaluation of bivariate associations between classifications of anthropometric indicators and the occurrence of wheezing. The logistic multivariate analyses used to study the association between anthropometric indicators and wheezing were adjusted for gender, age, per capita income, puberal development, caregiver education, number of people in household, level of physical activity, and presence of smokers in the house. The choice of variables for modeling was based on knowledge gathered from pre-existing literature (32).

The interaction was interpreted as a change in the magnitude of the effect in the presence of a third variable using the Wald test. The variables were classified as " interaction variables" when $\chi^{2}$ reached a $p$-value $\leq .05$.

The importance of each anthropometric indicator in determining wheezing was quantified by calculating the population attributable fraction (PAF) using the following formula: $[H-1 / H \times 100$, with $H=f 1 \times 1+f 2 \times \mathrm{OR} 2+f 3 \times \mathrm{OR} 3+f 4 \times \mathrm{OR} 4]$, where $f 1$ is the frequency of subjects in the baseline category of the anthropometric indicator (unexposed to risk); $f 2, f 3$, and $f 4$ are the frequencies in the risk categories of the indicator; and OR2, OR3, and OR4 are the adjusted odds ratios (ORs) for wheezing in each risk category for that indicator (33).

\section{Ethical Issues}

Ethical approval was provided by the Ethics Research Board of the School of Nutrition, Federal University of Bahia, Brazil, under registration number 27-09/CEPNUT, and the study was conducted in accordance with the Declaration of Helsinki of 1975, as revised in 2000. Written, informed consent detailing all procedures to be carried out was signed by a parent or legal guardian of each participant.

\section{RESULTS}

Of the total number of students initially selected (1500 students), 193 (12.8\%) declined or discontinued participation in the study (due to refusal, family moving to another city, or children transferring to another school), resulting in 1307 students of both sexes, aged 6-12 years. A total of 1187 students who presented complete information for the variables used here were included in the present analysis.

In the present study, there were slightly higher percentages of male students $(53.3 \%)$ and those aged between 6 and 10 years $(50.6 \%)$. Other characteristics of the studied population are shown in Table 1. It was also found that 10.6\% [confidence interval (CI): 95\% 8.9\%-12.31\%] of study participants had experienced wheezing within the last 12 months. Excess weight was observed in 16.2\% (CI 95\% 14.4\%-18.5\%) of the sample, as measured by BMI. Abdominal obesity, measured by WC and WHtR, was observed for $10.5 \%$ (CI: 95\% 8.5\%-12.2\%) and 7.9\% (CI: $95 \% 6.4 \%-93 \%$ ) of the study participants, respectively.

There were no associations between wheezing and demographic or socioeconomic factors. The level of physical activity and the presence of smokers in the house were

TABLE 1.-Characteristics of caregivers and children and adolescents aged 6-12 years enrolled in public schools in São Francisco do Conde, Bahia, Brazil, 2010.

\begin{tabular}{|c|c|c|c|c|c|}
\hline \multirow[b]{2}{*}{ Variables } & \multicolumn{2}{|c|}{$\begin{array}{l}\text { Population } \\
\text { number }\end{array}$} & \multicolumn{2}{|c|}{$\begin{array}{l}\text { Wheezing within } \\
\text { last } 12 \text { months }\end{array}$} & \multirow[b]{2}{*}{$p$-Value } \\
\hline & $n$ & $\%$ & $n$ & $\%$ & \\
\hline \multicolumn{6}{|l|}{ Gender } \\
\hline Male & 633 & 53.3 & 69 & 10.9 & \multirow[t]{2}{*}{.657} \\
\hline Female & 554 & 46.7 & 56 & 10.1 & \\
\hline \multicolumn{6}{|l|}{ Age (years) } \\
\hline 6 to $<10$ & 601 & 50.6 & 71 & 11.8 & \multirow[t]{2}{*}{.145} \\
\hline$\geq 10$ to $<13$ & 586 & 49.4 & 54 & 9.2 & \\
\hline \multicolumn{6}{|c|}{ Pubertal development } \\
\hline Prepubertal & 712 & 60.0 & 72 & 10.1 & \multirow[t]{2}{*}{.565} \\
\hline Pubertal & 475 & 40.0 & 53 & 11.2 & \\
\hline \multicolumn{6}{|c|}{ Caregiver education } \\
\hline$\geq 4$ years & 820 & 69.1 & 84 & 10.2 & \multirow[t]{2}{*}{.630} \\
\hline$<4$ years & 367 & 30.9 & 41 & 11.2 & \\
\hline \multicolumn{6}{|c|}{ Per capita income $\mathrm{e}^{\mathrm{a}, \mathrm{b}}$} \\
\hline$>1 \mathrm{MS}$ & 945 & 79.7 & 95 & 10.1 & \multirow[t]{2}{*}{.270} \\
\hline$\leq 1 \mathrm{MS}$ & 240 & 20.3 & 30 & 12.5 & \\
\hline \multicolumn{6}{|c|}{ Household location } \\
\hline Rural & 779 & 65.6 & 73 & 9.4 & \multirow[t]{2}{*}{.072} \\
\hline Urban & 408 & 34.4 & 52 & 12.7 & \\
\hline \multicolumn{6}{|c|}{ No. of people at the household } \\
\hline$\leq 3$ & 281 & 23.7 & 24 & 8.5 & \multirow[t]{2}{*}{.214} \\
\hline$>3$ & 906 & 76.3 & 101 & 10.8 & \\
\hline \multicolumn{6}{|c|}{ Level of physical activity ${ }^{\mathrm{b}}$} \\
\hline Active & 285 & 24.0 & 16 & 8.0 & \multirow[t]{2}{*}{.120} \\
\hline & 902 & 76.0 & 109 & 11.3 & \\
\hline \multicolumn{6}{|c|}{ Smokers at the household ${ }^{\mathrm{b}}$} \\
\hline No & 929 & 79.9 & 92 & 9.9 & \multirow[t]{2}{*}{.131} \\
\hline Yes & 223 & 20.1 & 31 & 13.3 & \\
\hline
\end{tabular}

Notes: ${ }^{a}$ Measured in Brazilian minimum salary (BMS; value in 2010; BRL510.00, equivalent to US\$290.7). ${ }^{\mathrm{b}}$ Different totals because of nonavailable data. 
TABLE 2.-Crude and adjusted ORs of the association between excess weight and asthma among children and adolescents enrolled in public schools in São Francisco do Conde, Bahia, Brazil, 2010.

\begin{tabular}{|c|c|c|c|c|c|c|}
\hline \multirow[b]{2}{*}{ Variables } & \multicolumn{2}{|c|}{ Studied population } & \multicolumn{2}{|c|}{ Wheezing } & \multirow[b]{2}{*}{ Crude OR (IC95\%) } & \multirow[b]{2}{*}{ Adjusted OR (IC95\%) } \\
\hline & $n$ & $\%$ & $n$ & $\%$ & & \\
\hline \multicolumn{7}{|l|}{ BMI } \\
\hline$<85$ & 995 & 83.3 & 99 & 9.6 & 1 & \\
\hline$\geq 85$ & 192 & 16.2 & 26 & 13.5 & $1.41(0.89-2.51)$ & $1.61(1.02-2.68)$ \\
\hline $\mathrm{PAF}^{\mathrm{b}}(\%)$ & 8.2 & & & & & \\
\hline \multicolumn{7}{|l|}{$\mathrm{WC}$} \\
\hline$<85$ & 1061 & 89.5 & 106 & 10.0 & 1 & 1 \\
\hline$\geq 85$ & 125 & 10.5 & 19 & 15.2 & $1.61(0.95-2.73)$ & $1.78(1.03-3.07)$ \\
\hline $\mathrm{PAF}^{\mathrm{b}}(\%)$ & 7.3 & & & & & \\
\hline \multicolumn{7}{|l|}{ WHtR } \\
\hline$<0,50$ & 1092 & 92.1 & 109 & 10.0 & 1 & 1 \\
\hline$\geq 0.50$ & 94 & 7.9 & 16 & 17.0 & $1.85(1.04-3.28)$ & 2.01(1.11-3.65) \\
\hline $\mathrm{PAF}^{\mathrm{b}}(\%)$ & 7.1 & & & & & \\
\hline
\end{tabular}

Notes: a Adjusted for gender, age, per capita income, puberal development, caregiver education, number of people in household, level of physical activity, and presence of smokers in the house. ${ }^{b}$ Population attributed fraction. Boldface numbers are statistically significant.

not significantly different between those who had or had not experienced wheezing in the previous 12 months (Table 1).

The data were analyzed by multivariate unconditional logistic regression, adjusted for gender, age, per capita income, pubertal development, caregiver education, the number of people in the household, physical activity level, and the presence of smokers in the house. Obesity was significantly associated with wheezing, as assessed by BMI $(\mathrm{OR}=1.61, \mathrm{CI}: 95 \% 1.02$ to 2.68$)$, WC $(\mathrm{OR}=1.78$, CI: 95\% 1.03-3.07), and WHtR $(\mathrm{OR}=2.01$, CI: 95\% 1.11-3.65) (Table 2; Supplementary Table). There were no significant interactions between gender and the anthropometric indicators (gender_WC $p=.134$, gender_WHtR $p=.074$, gender_BMI $p=.715$ ). In addition to the adjusted ORs, the corresponding fractions of disease attributable to anthropometric indicators (PAFs) are presented in Table 2 . The fraction of wheezing attributable to BMI $(8.2 \%)$ slightly exceeded the fraction identified for abdominal obesity, as measured by WC (7.3\%) and WHtR (7.1\%).

\section{DISCUSSION}

During the previous 12 months, $10.6 \%$ of the studied individuals had experienced wheezing according to the mother. This prevalence is lower than those recorded in other regions of Brazil (1). A possible explanation for this phenomenon is that most studies in Brazil have been held in large cities, while the present study was conducted in a small town and its surrounding rural areas. However, this prevalence is consistent with those described in urban areas of Argentina, Chile, and Mexico (1). The prevalence of overweight children (16.2\%) was slightly higher than that reported previously by Souza (34) and Matos et al. (35) in Salvador, but was consistent with those identified by the vast majority of other studies among children and adolescents in other regions of Brazil (6).

The results of multiple logistic regression analysis showed, after adjustment, positive and significant association of all anthropometric indicators with wheezing. Thus, in the present study, participants with excess weight, as measured by BMI $\geq 85$ th percentile, WC $\geq 80$ th percentile, and WHtR $>0.5$, were $61 \%, 78 \%$, and $100 \%$ more likely to have experienced wheezing, respectively. The results of this study reinforce the influence of excess weight in the occurrence of wheezing, which has also been reported by other studies in Brazil (35-37) and elsewhere $(38,39)$ in populations of the same age range.

Another important finding in the present study was the absence of major differences in the fraction of wheezing attributable to the three anthropometric indicators used (range 7.0 to $8.2 \%$ ). To the best of our knowledge, only one study in the literature on this subject used the PAF to evaluate the importance of excess weight in determining asthma (40). In that study, the PAF estimated that $28 \%$ of asthma occurring in women after age 9 was due to excess weight (40), as measured by BMI. In the present work, the explanatory power of these indicators for the occurrence of wheezing was slightly higher for BMI than for abdominal obesity. This suggests that greater fat deposits, either in the abdominal region or elsewhere in the body, increase the risk of wheezing. We know of no other study employing the same analytical procedure to evaluate the role of anthropometric indices on the occurrence of asthma or wheezing; the PAF is commonly used in studies assessing risk factors for cardiac diseases $(41,42)$. Thus, comparisons between reports in the literature and the present study are not straightforward. For instance, our results differ from those reporting greater robustness of abdominal obesity compared to standard BMI measures in the occurrence of wheezing (or asthma) in children and adolescents (19) or adults (43).

BMI, WC, and WHtR correlate with the amount of visceral adipose tissue, although some studies have shown the WC to be the anthropometric measure that best correlates with the amount of visceral adipose tissue (44). Visceral adipose tissue is considered a risk factor for various metabolic disorders and cardiovascular risk at all stages of life (45-47). Insulin resistance and metabolic syndrome appear to increase 
the risk of asthma occurrence (48). However, the mechanisms by which these illnesses promote wheezing/asthma have not yet been clearly elucidated. Obesity has more recently been thought of as an inflammatory condition because proinflammatory cytokines produced by adipocytes, such as IL-1, TNF-alpha, leptin, and adiponectin, lead the immune system toward a $\mathrm{T}_{\mathrm{h}} 2$ response. Such polarization might, consequentially, worsen a pre-existing sensitization, thus pushing the individual to develop asthma and rhinitis (49). In obese people, symptoms of breathlessness and wheezing may be due to the increased work of breathing (50). Alternatively, obesity may have a direct effect on the respiratory system physiology by altering lung volume, airway calibre, or respiratory muscle strength (51). In addition to the quantity of fat, the distribution of fat may also play a role in wheezing (asthma). Adipose tissue in the chest and abdomen leads to a reduction of lung tidal volume and functional residual capacity (52). Even without considering the distribution of fat, pulmonary function has been shown to be impaired in the presence of obesity, such as in children in Salvador-Brazil, where overweight children had higher rates of asthma and reduced respiratory capacity (35).

It should be noted that this study has limitations inherent to cross-sectional studies, particularly in estimating relationships between the variables, response, and exposure simultaneously, as well as not considering the temporality between events. Thus, this study design did not allow us to establish a cause and effect relationship. However, improvements in respiratory function with weight reduction have been demonstrated in adults (53) and children (54). It has been suggested that increases in obesity may have contributed to the rise in wheezing or asthma. In this study, a report of wheezing in the past 12 months was used as an outcome, as in other population-based studies. While the lack of asthma diagnosis by a physician and medication usage could be interpreted as limitations of the study, the report of symptoms (wheezing) is less dependent on access and quality of health services. However, The ISAAC questionnaire showed good specificity and sensibility for using in worldwide multicenter surveys (55). In Brazil, a validation study showed that wheezing in the past 12 months had high values of sensitivity, specificity, and positive and negative predictive values, reinforcing the concept that this is the key question for the diagnosis of asthma (56). Conversely, the following are the strengths of the study: the control for confounding variables relevant to estimating the association between anthropometric indicators and asthma and the analytical procedures employed to ensure comparability in assessing the explanatory power of anthropometric indices in determining asthma.

\section{CONCLUSION}

In summary, we found a statistically significant association between the prevalence of wheezing and multiple measures of body size, confirming previous studies showing excess weight/obesity in the occurrence of wheezing or asthma. Our results suggest that an increase in fat deposits, either in the abdominal region or elsewhere in the body, increases the risk of wheezing. Because excess weight/obesity is an important public health problem, its control may reduce the occurrence of wheezing and asthma. Studies focusing on the mechanisms involved in the association between obesity and both wheezing and asthma should aim to improve preventive and therapeutic approaches for both illnesses.

\section{NOTES ON CONTRIBUTORS}

Rita de Cássia Ribeiro Silva participated in the study design, the data collection, the interpretation of results and in writing the article. Ana Marlúcia Oliveira Assis participated in the interpretation of results and writing the article. Luce Alves da Silva participated in the field work and reviewed the article. Rosemeire Leovigildo Fiaccone designed the work and reviewed the article. Mauricio L Barreto, Elizabete de Jesus Pinto, Marilda Souza Goncalves, Sheila Maria Alvim Matos, and Laura C. Rodrigues participated in the interpretation of results and revision of the article. Neuza Maria Alcantara-Neves participated in the study design and the revision of the article.

\section{DECLARATION OF INTEREST}

The authors report no conflicts of interest. The authors alone are responsible for the content and writing of the article. Fundação de Amparo à Pesquisa do Estado da Bahia - FAPESB- Projects nos. 7638/2009 and 7597/ 2009 and Coordenação de Aperfeiçoamento de Pessoal de Nível Superior (CAPES) - Process no. 1254/10-3.

\section{REFERENCES}

1. Cooper PJ, Rodrigues LC, Cruz AA, Barreto ML. Asthma in Latin America: A public heath challenge and research opportunity. Allergy 2009; 64(1):5-17

2. Solé D, Wandalsen GF, Camelo-Nunes IC, Naspitz CK. Prevalence of symptoms of asthma, rhinitis, and atopic eczema among Brazilian children and adolescents identified by the International Study of Asthma and Allergies in Childhood (ISAAC): Phase 3. Jornal De Pediatria 2006; 82:341-346.

3. Feitosa CA, Santos DN, Barreto do Carmo MB, Santos LM, Teles CA, Rodrigues LC, Barreto ML. Behavior problems and prevalence of asthma symptoms among Brazilian children. J Psychosom Res 2011; 71(3):160165.

4. von Mutius E, Schwartz J, Neas LM, Dockery D, Weiss ST. Relation of body mass index to asthma and atopy in children: The National Health and Nutrition Examination Study III. Thorax 2001 Nov; 56(11):835-838.

5. Zotor FB, Amuna P. The food multimix concept: New innovative approach to meeting nutritional challenges in Sub-Saharan Africa. Proc Nutr Soc 2008; 67(1):98-104.

6. Batista Filho M, Rissin A. Nutritional transition in Brazil: Geographic and temporal trends). Cad Saude Publica 2003; 19(Suppl 1):S181-91.

7. Brazilian Institute of Geography and Statistics. POF 2008-2009: Anthropometry and nutritional status of children, adolescents and adults in Brazil. Brazilian Institute of Geography and Statistics - IBGE [On-line]. 2010 Available at: http://www.ibge.gov.br. [Accessed Jun 29 2011].

8. Tsai AG, Abbo ED, Ogden LG. The time burden of overweight and obesity in primary care. BMC Health Serv Res 2011; 11:191. 
9. Ford ES. The epidemiology of obesity and asthma. J Allergy Clin Immunol 2005; 115(5):897-909. quiz 10.

10. Beuther DA. Recent insight into obesity and asthma. Curr Opin Pulm Med 2010; 16(1):64-70.

11. Neovius M, Linne Y, Barkeling B, Rossner S. Discrepancies between classification systems of childhood obesity. Obes Rev 2004; 5(2):105-114.

12. Haun DR, Pitanga FJ, Lessa I. Waist-height ratio compared to other anthropometric indicators of obesity as predictors of high coronary risk. Rev Assoc Med Bras 2009; 55(6):705-711.

13. Kahn HS, Imperatore G, Cheng YJ. A population-based comparison of BMI percentiles and waist-to-height ratio for identifying cardiovascular risk in youth. J Pediatr 2005; 146(4):482-488.

14. Alvarez MM, Vieira ACRE, Sicheri R, Da Veiga GV. Association between central body anthropometric measures and metabolic syndrome components in a probabilistic sample of adolescents from public schools. Arq Bras Endocrinol 2008; 52(4):649-657.

15. Valdez R, Seidell JC, Ahn YI, Weiss KMA. New Index of Abdominal Adiposity as an Indicator of Risk for Cardiovascular-Disease-a CrossPopulation Study. Int J Obesity 1993; 17(2):77-82.

16. Ashwell M, Hsieh SD. Six reasons why the waist-to-height ratio is a rapid and effective global indicator for health risks of obesity and how its use could simplify the international public health message on obesity. Int J Food Sci Nutr 2005; 56(5):303-307.

17. Cowan K, Guilbert TW. Pediatric asthma phenotypes. Curr Opin Pediatr 2012; 24(3):344-351.

18. Vangeepuram N, Teitelbaum SL, Galvez MP, Brenner B, Doucette J, Wolff MS. Measures of obesity associated with asthma diagnosis in ethnic minority children. J Obes 2011; 2011:517417.

19. Musaad SM, Patterson T, Ericksen M, Lindsey M, Dietrich K, Succop P, Khurana Hershey GK. Comparison of anthropometric measures of obesity in childhood allergic asthma: Central obesity is most relevant. J Allergy Clin Immunol 2009; 123(6):1321-7 e12.

20. Tantisira KG, Litonjua AA, Weiss ST, Fuhlbrigge AL. Association of body mass with pulmonary function in the Childhood Asthma Management Program (CAMP). Thorax 2003; 58(12):1036-1041.

21. Superintendência de Estudos Econômicos. Índice de Desenvolvimento Econômico e Social dos Municípios Baianos. Salvador: Superintendência de Estudos Econômicos, 2008.

22. Sole D, Vanna AT, Yamada E, Rizzo MC, Naspitz CK. International Study of Asthma and Allergies in Childhood (ISAAC) written questionnaire: Validation of the asthma component among Brazilian children. J Investig Allergol Clin Immunol 1998; 8(6):376-382.

23. Lohman TG, Roche AF, Martorell R. Anthropometric Standardization Reference Manual. Champaign, IL: Human Kinetics Books, 1988, vi:177.

24. WHO (2007). de Onis M, Onyango AW, Borghi E, Siyam A, Nishida C, Siekmann J. Development of a WHO growth reference for school-aged children and adolescents. Bull World Health Organ 2007 Sep;85(9): $660-7$.

25. WHO Multicentre Growth Reference Study Group. WHO Child Growth Standards: Length/Height-for-Age W-F-A, Weight-for-Length, Weightfor-Height and Body Mass Index-for-Age: Methods and Development. Geneva: World Health Organization, 2006.

26. Gillum RF. Distribution of waist-to-hip ratio, other indices of body fat distribution and obesity and associations with HDL cholesterol in children and young adults aged 4-19 years: The Third National Health and Nutrition Examination Survey. Int J Obes Relat Metab Disord 1999; 23(6):556-563.

27. Taylor RW, Jones IE, Williams SM, Goulding A. Evaluation of waist circumference, waist-to-hip ratio, and the conicity index as screening tools for high trunk fat mass, as measured by dual-energy X-ray absorptiometry, in children aged 3-19 y. Am J Clin Nutr 2000; 72(2):490-495.

28. Garnett SP, Baur LA, Cowell CT. Waist-to-height ratio: A simple option for determining excess central adiposity in young people. Int J Obes (Lond 2008 Jun; 32(6): 1028-1030.

29. Pate RR, Freedson PS, Sallis JF, Taylor WC, Sirard J, Trost SG, Dowda M. Compliance with physical activity guidelines: Prevalence in a population of children and youth. Ann Epidemiol 2002; 12(5): 303-308.

30. Marshall WA, Tanner JM. Variations in the pattern of pubertal changes in boys. Arch Dis Child 1970; 45(239):13-23.
31. Marshall WA, Tanner JM. Variations in pattern of pubertal changes in girls. Arch Dis Child 1969; 44(235):291-303.

32. Pearce N, Douwes J. The global epidemiology of asthma in children. Int J Tuberc Lung Dis 2006; 10(2):125-132.

33. Kleinbaum DG, Kupper LL, Morgenstern H. Epidemiologic Research: Principles and Quantitative Methods. New York: Lifetime Learning Publications, 1982:160-164.

34. Souza CO, Silva RdeC, Assis AMO, Fiaccone RL, Pinto EJ, Moraes LTLPd. Association between physical inactivity and overweight among adolescents in Salvador, Bahia-Brazil. Rev Bras de Epidemiol 2010; $13: 468-475$.

35. Matos SM, Jesus SR, Saldiva SR, Prado MS, D'Innocenzo S, Assis AM, Rodrigues LC, Alcantara-Neves NM, Cruz ÁA, Simões Sde M, Barreto ML; SCAALA (Social Change, Asthma and Allergy in Latin America) Study Group. Overweight, asthma symptoms, atopy and pulmonary function in children of 4-12 years of age: Findings from the SCAALA cohort in Salvador, Bahia, Brazil. Public Health Nutr 2011; 14:1270-8.

36. Saldiva SRDM, Escuder MM, Venancio SI, Benici MHA, Assis AMO, Oliveira LPM, Barreto ML. Is overweight a risk factor for wheezing in pre-school children? A study in 14 Brazilian communities. Public Health Nutr 2007; 10(9):878-882.

37. Cassol VE, Rizzato TM, Teche SP, Basso DF, Centenaro DF, Maldonado M, Moraes EZ, Hirakata VN, Solé D, Menna-Barreto SS. Obesity and its relationship with asthma prevalence and severity in adolescents from southern Brazil. J Asthma 2006; 43(1):57-60.

38. Vazquez-Nava F, Romero JM, Fernandez AC, Saldivar-Gonzalez AH, Vazquez-Rodriguez CF, Gomez MDB, Lin-Ochoa D, Vázquez Rodríguez EM. Association between Obesity and Asthma in Preschool Mexican Children. Scientific World Journal 2010; 10:1339-46.

39. Song Y, Kim B, Yu J, Kim H, Kim W, Lee S, et al. Positive Association Between Obesity, Asthma, And Lung Function In Young Korean Boys. J Allergy Clin Immun 2009; 123(2):S20-S.

40. Hancox RJ, Milne BJ, Poulton R, Taylor DR, Greene JM, McLachlan CR, Cowan JO, Flannery EM, Herbison GP, Sears MR. Sex differences in the relation between body mass index and asthma and atopy in a birth cohort. Am J Respir Crit Care Med 2005; 171(5):440-445.

41. Sarno F, Monteiro CA. Relative importance of body mass index and waist circumference for hypertension in adults. Revista de Saúde Pública 2007; 41:788-796.

42. Okosun IS, Cooper RS, Rotimi CN, Osotimehin B, Forrester T. Association of waist circumference with risk of hypertension and type 2 diabetes in Nigerians, Jamaicans, and African-Americans. Diabetes Care 1998; 21(11):1836-1842.

43. Kronander UN, Falkenberg M, Zetterstrom O. Prevalence and incidence of asthma related to waist circumference and BMI in a Swedish community sample. Respir Med 2004; 98(11):1108-1116.

44. Seidell JC, Kahn HS, Williamson DF, Lissner L, Valdez R. Report from a Centers for Disease Control and Prevention Workshop on use of adult anthropometry for public health and primary health care. Am J Clin Nutr 2001; 73(1):123-126.

45. Ritchie SA, Connell JM. The link between abdominal obesity, metabolic syndrome and cardiovascular disease. Nutr Metab Cardiovasc Dis 2007; 17(4):319-326.

46. Iwashima S, Nakagawa Y, Ishikawa T, Satake SS, Nagata E, Ohzeki T. Abdominal obesity is associated with cardiovascular risk in Japanese children and adolescents. J Pediatr Endocrinol Metab 2011; 24(1-2):51-54.

47. Brufani C, Fintini D, Giordano U, Tozzi AE, Barbetti F, Cappa M. Metabolic syndrome in italian obese children and adolescents: Stronger association with central fat depot than with insulin sensitivity and birth weight. Int J Hypertens 2011; 2011:257168.

48. Al-Shawwa BA, Al-Huniti NH, DeMattia L, Gershan W. Asthma and insulin resistance in morbidly obese children and adolescents. J Asthma 2007; 44(6):469-473.

49. Ciprandi G, Caimmi D, Raschetti R, Miraglia Del Giudice M, Salpietro $\mathrm{C}$, Caimmi S, et al. Adipokines and their role in allergies. Int $\mathrm{J}$ Immunopathol Pharmacol 2011; 24(4 Suppl):13-16. 
50. Martinez FJ, Stanopoulos I, Acero R, Becker FS, Pickering R, Beamis JF. Graded comprehensive cardiopulmonary exercise testing in the evaluation of dyspnea unexplained by routine evaluation. Chest 1994; 105 (1):168-174

51. Luce JM. Respiratory complications of obesity. Chest 1980 Oct; 78(4):626-631.

52. Shore SA, Fredberg JJ. Obesity, smooth muscle, and airway hyperresponsiveness. J Allergy Clin Immun 2005; 115(5):925-927.

53. Flaherman V, Rutherford GW. A meta-analysis of the effect of high weight on asthma. Arch Dis Child 2006; 91(4):334-339.
54. Masumoto N, Odajima H, Shimada K, Murakami Y, Motomura C, Honjo S, Okada K. Effect of weight reduction on respiratory function in obese children with asthma. Arerugi 2011 Aug; 60(8): 983-992.

55. Worldwide variation in prevalence of symptoms of asthma, allergic rhinoconjunctivitis, and atopic eczema: ISAAC. The International Study of Asthma and Allergies in Childhood (ISAAC) Steering Committee. Lancet 1998; 351(9111):1225-1232.

56. Wandalsen NF, Gonzalez C, Wandalsen GF, Solé D. Evaluation of criteria for the diagnosis of asthma using an epidemiological questionnaire. J Bras Pneumol 2009; 35:199-205. 
Copyright of Journal of Asthma is the property of Taylor \& Francis Ltd and its content may not be copied or emailed to multiple sites or posted to a listserv without the copyright holder's express written permission. However, users may print, download, or email articles for individual use. 